Portland State University

PDXScholar

6-13-1982

\title{
Correlates of Sophisticated Listener Judgments of Esophageal Air Intake Noise
}

Vincent Eccleston

Portland State University

Follow this and additional works at: https://pdxscholar.library.pdx.edu/open_access_etds

Part of the Speech Pathology and Audiology Commons Let us know how access to this document benefits you.

\section{Recommended Citation}

Eccleston, Vincent, "Correlates of Sophisticated Listener Judgments of Esophageal Air Intake Noise" (1982). Dissertations and Theses. Paper 3181.

https://doi.org/10.15760/etd.3170

This Thesis is brought to you for free and open access. It has been accepted for inclusion in Dissertations and Theses by an authorized administrator of PDXScholar. Please contact us if we can make this document more accessible: pdxscholar@pdx.edu. 
AN ABSTRACT OF THE THESIS OF Vincent Eccleston for the Master of Science in Speech Communication: Emphasis in Speech Pathology/Audiology presented June 13, 1982.

Title: Correlates of Sophisticated Listener Judgments of Esophageal Air Intake Noise.

APPROVED BY MEMBERS OF THE THESIS COMMITTEE:

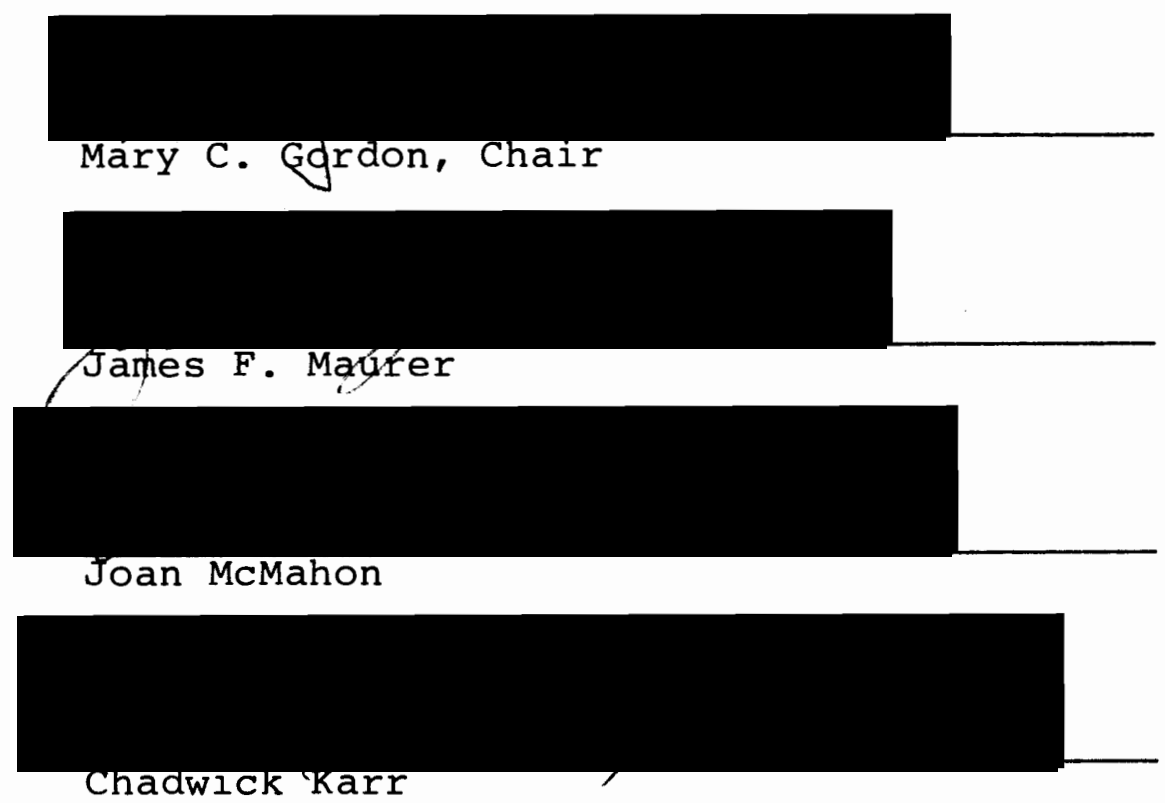

The literature on esophageal speech has identified the problem of extraneous air intake noise, suggested its possible etiology, and provided practical advice for clinical management. Documentation on the efficacy of specific methodology is lacking in the literature. Such documentation would be simplified if objective criteria were used to 
rate the severity of intake noise. The present study was prompted by the lack of basic data regarding listener evaluation of intake noise.

The purpose of this study was to identify physical and perceptual correlates of acceptability of esophageal air intake noise. A primary and a secondary question were asked:

Are selected objective measures of esophageal speech significantly correlated with sophisticated listener judgments of air intake noise acceptability? The measures used were:

1. The mean intensity of air intake noise

2. The mean intensity of speech

3. The ratio of mean speech intensity to mean intake noise intensity

4. The number of syllables uttered per intake

5. The rate of speech (in syllables per second)

Secondarily, are sophisticated listener judgments of overall esophageal speech proficiency significantly correlated with sophisticated listener judgments of air intake noise acceptability?

Twenty-four laryngectomees, ranging widely in esophageal speaking ability, read a standard passage for audio tape recording. Four expert voice clinicians listened to the tapes, rating subjects on the acceptability of air intake noise. Overall esophageal speech proficiency ratings 
for eighteen of the subjects were obtained from an independent study conducted during the same week.

Five objective measures of esophageal speech were extracted from each speech sample, using a real-time intensity display instrument and a storage oscilloscope.

Interjudge and intrajudge reliability were determined by computing Pearson product-moment correlation coefficients. The means of the ratings on intake noise acceptability were entered in a multiple regression analysis as the criterion variable, with the objective measurements and the overall speech proficiency ratings as the predictor variables.

Three of the predictor variables were found to be positively correlated with the air intake acceptability ratings beyond the .01 level of significance: the number of syllables uttered per air intake, the mean intensity of intake, and the rate of speech. The ratio of mean speech intensity to mean intake noise intensity was correlated to intake noise acceptability at the .05 level. Neither mean speech intensity nor the overall esophageal speech proficiency variables were significantly correlated with intake noise acceptability. The number of syllables uttered per intake accounted for the largest share of the variance of intake noise acceptability. Mean intake intensity was the second, but far weaker predictor of variance. The remaining 
variables accounted for a very slight percentage of the total variance. 


\title{
CORRELATES OF SOPHISTICATED LISTENER JUDGMENTS \\ OF ESOPHAGEAL AIR INTAKE NOISE
}

by

VINCENT ECCLESTON
A thesis submitted in partial fulfillment of the requirements for the degree of

\author{
MASTER OF SCIENCE \\ in \\ SPEECH COMMUNICATION \\ With emphasis in \\ Speech Pathology/Audiology \\ Portland State University \\ 1982
}




\section{ACKNOWLEDGEMENTS}

I am indebted to many talented people who gave of their time, knowledge and resources to further this research effort. Above all, I thank my wife Stella, whose unstinting patience and confidence were my most precious resources. Many thanks to Dr. Herbert Gunderson, his faculty and staff, and the attendees of the 14 th Annual Institute in Laryngectomee Rehabilitation at Eastern Washington University for their warm welcome and enthusiastic cooperation. A special thanks to Doctors Daniel Boone, Albert Knox and Paul Moore for their genuine interest and gracious participation in this study. Dr. Knox's generous contribution of his time, technical expertise and laboratory instrumentation were of critical importance to this project and were greatly appreciated.

Thanks are extended to my graduate research committee: Professors Mary Gordon, James Maurer, Joan McMahon and Chadwick Karr. Their insightful questions and valuable suggestions significantly improved the accuracy and readibility of this research paper. I am especially grateful to Professors Maurer and Gordon for their advice and encouragement during periods of exasperating technical complication.

Thanks also to Dr. Ted Grove for sharing his knowledge of statistical design and for introducing me to our 
university's computer. Ms. Karen Kumpala and Ms. Corinne Thomas-Kersting unselfishly contributed their time to help me create a data file. Gordon R. Frey provided superb tape recorder service and tape dubbing.

To my graduate advisor, Professor Joan McMahon, and all my professors and instructors in Portland State University's Speech and Hearing Sciences Program, I want to express my sincere appreciation for their obvious devotion to their students and profession. 
TABLE OF CONTENTS

PAGE

ACKNOWLEDGEMENTS • • • • • • • • • • • • • • • • iii

LIST OF TABLES . . . . . . . . . . . . . . . . viii

LIST OF FIGURES . . . . . . . . . . . . . . . . . . . ix

CHAPTER

I INTRODUCTION

Statement of Purpose . . . . . . 3

II REVIEW OF THE LITERATURE . . . . . . . . 5

III METHODS AND PROCEDURES . . . . . . . . 11

Subjects . . . . . . . . . . . 11

Recording Equipment and Procedures . . 11

Rating Sessions . . . . . . . . 12

Judges

Equipment and Procedures for Air

Intake Acceptability Ratings

Procedures for Overall Proficiency

Ratings

Raw Data Analysis . . . . . . .

Instrumentation

Procedures

Statistical Analysis . . . . . .

Interjudge Reliability

Intrajudge Reliability

Correlation of Objective Measurements with Listener Judgments of Acceptability 
Association of Listener Judgments of Speech Proficiency and Noise Acceptability

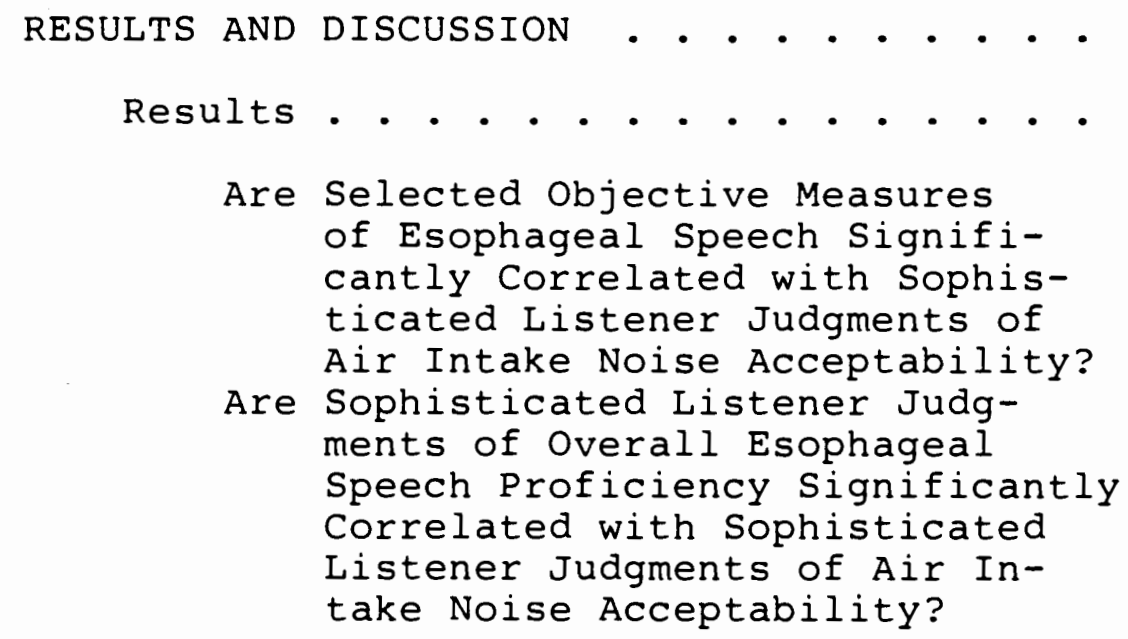

Are Selected Objective Measures of Esophageal Speech Significantly Correlated with Sophisticated Listener Judgments of Air Intake Noise Acceptability?

Are Sophisticated Listener Judgments of Overall Esophageal Speech Proficiency Significantly Correlated with Sophisticated Listener Judgments of Air Intake Noise Acceptability?

Are Selected Objective Measures of Esophageal Speech Significantly Correlated with Sophisticated Listener Judgments of Air Intake Noise Acceptability?

Are Sophisticated Listener Judgments of Overall Esophageal Speech Proficiency Significantly Correlated with Sophisticated Listener Judgments of Air Intake Noise Acceptability?

Future Research 
APPENDICES • • • • • • • • • • • • • • • • • • • 35

A INSTRUCTIONS READ TO JUDGES • • • • • • • 35

B ESOPHAGEAL SPEECH PROFICIENCY SCALE USED BY THE $14 \mathrm{TH}$ ANNUAL INSTITUTE IN LARYNGECTOMEE REHABILITATION, EASTERN WASHINGTON UNIVERSITY, 1981 


\section{LIST OF TABLES}

\section{TABLE}

PAGE

I Correlation between Each Judge's Ratings and the Mean-of-Judges Rating . . . .

I Correlation between Each Judge's Test and Retest Ratings of Selected Subjects • • • . . . . . . . . • •

II Correlation Matrix for Esophageal Intake Noise Acceptability . . . . . . . . . 


\section{LIST OF FIGURES}

FIGURE

PAGE

1. Overlay Traced from a Photograph of

Visi-pitch, Model 6087, Display of

the Esophageal Speech Sample from

Subject Number 5. Asterisks Repre-

sent Esophageal Air Intakes . . . . . . 16 


\section{CHAPTER I}

\section{INTRODUCTION}

Advances in surgical technique and post-operative care have dramatically increased the survival rate of persons requiring total surgical removal of the larynx. The American Cancer Society (1978) reports that approximately 80 percent of laryngectomized persons live at least five years after surgery, and that approximately 70 percent survive ten years or more. Survival, however, is only the first critical step in a series of challenges to be met by the recovering laryngectomee. In a society which highly values verbal exchange, the loss of voice may have a devastating impact on one's employment, social relationships, and self-esteem. The acquisition of adequate alaryngeal voice is a major goal in the successful rehabilitation of the laryngectomized individual.

It is estimated that 50 to 70 percent of laryngectomized individuals utilize esophageal speech as their primary means of communication (Gardner, 1978; Horn, 1962).

Studies of listener evaluation of esophageal speech indicate considerable variability in levels of vocal proficiency (Shames, Font, \& Mathews, 1963; Shipp, 1967; Snidecor, 1968). When compared with normal speech, esophageal speech 
has inherent limitations on rate, volume, and pitch. Despite these apparent limitations, a skilled esophageal speaker communicates effectively with most listeners in relatively quiet environments.

Snidecor (1968) has stated that certain extraneous noises produced by some esophageal speakers may be problematic. Many esophageal speakers produce unwanted noise when taking air into the esophagus for use in speech. The injection method of esophageal insufflation has been associated with a low-frequency noise which is often referred to as a klunk (Diedrich \& Youngstrom, 1966). This air intake noise has been variously described as sounding like "thump," "punk," or "clump" (Snidecor, 1968) or as a loud gulp (Greene, 1957; Hyman, 1971). Klunk seems to be the term most widely accepted, and will be used in this paper. The klunk may range in character from an infrequent, barely audible sound to a very distracting noise which may equal or exceed phonation intensity and may be produced one or more times per air charge.

Gardner (1978) and Shanks (1977) suggest that once klunking behavior is established, it is very difficult to extinguish. Although many authors suggest clinical approaches to minimize or eliminate klunking noise, very little is published regarding incidence or etiology. Many questions remain unanswered. For example, what acoustic parameters contribute to the listener's perception of air 
intake noise as a klunk? When, if ever, is air intake noise severe enough to interfere with communication? At what stage in treatment might a clinician overlook the production of air intake noise in deference to other aspects of esophageal speech? In the absence of published information on these questions, it would seem such decisions are presently made on the basis of clinical experience. While there is no substitute for good clinical judgment, it is possible that clinicians lack objective criteria for determining acceptability of esophageal air intake noise.

\section{STATEMENT OF PURPOSE}

This study sought to identify physical and perceptual correlates for listener acceptability of esophageal air intake noise. The primary research question asked was: are selected objective measurements of esophageal speech significantly correlated with sophisticated listener judgments of air intake noise acceptability? The specific measurements used in this study are listed below.

1. The mean intensity of air intake noise

2. The mean intensity of speech

3. The ratio of mean speech intensity to mean intake noise intensity

4. The number of syllables uttered per intake

5. The rate of speech (in syllables per second) 
A secondary research question was also asked: are sophisticated listener judgments of overall esophageal speech proficiency significantly correlated with sophisticated listener judgments of air intake noise acceptability? 
CHAPTER II

REVIEW OF THE LITERATURE

Numerous authors have identified air intake noise as a problem for many esophageal speakers, and/or have suggested instructional treatment procedures (Diedrich, 1968; Gardner, 1978; Greene, 1957; Hyman, 1971, 1979; Kallen, 1934;

Luchsinger \& Arnold, 1965; Salmon, 1971; Shanks, 1979; Snidecor, 1968; Waldrop, 1956). Diedrich and Youngstrom (1966), Martin (1963), and Shanks (1977, 1979) have speculated on the possible etiology of klunking noise. Diedrich and Youngstrom (1966) have published empirical evidence which appears to associate the production of klunking noises with a particular method of esophageal air intake. Shames, Font, and Mathews (1963) studied the relationship of instructional practices with the level of esophageal speech proficiency, but did not include the parameter of air intake noise.

The etiology of klunking noise is unclear. A frequent explanation is "too much air taken in too fast, and in too tense a manner" (Diedrich, 1971). Similar explanations are found in Hyman (1971), Duguay (1977), and Martin (1979). Shanks (1977) suggests the noise is produced by a partial vacuum, created when the Pharyngeal-Esophageal (PE) segment 
is rapidly lowered as the bolus of air enters the esophagus. Additionally, he associates klunking noise with the injection method of esophageal air intake. Diedrich and Youngstrom (1966) support such an association with their cinefluorographic studies. The injection technique relies on the increase of air pressure in the oral-pharyngeal cavity by a pump-like movement of the tongue. When intra-oral air pressure is sufficient to push the bolus past the PE segment, the esophagus is partially inflated. Martin (1963) states the probable cause of intake noise is the inability of the speaker to sufficiently relax the PE segment, which may act as a sphincter. Greene (1957), Hyman (1971), and Salmon (1971) suggest that excessive muscular tension of perhaps one or more of the oral structures may contribute to unwanted noise production.

This survey of the literature found no data on the incidence of klunking in esophageal speakers. It could be inferred from descriptions by Duguay (1977) and Lauder (1972) about the learning of the injection method of intake, that some air intake noise is evident in many beginning speakers. Luchsinger and Arnold (1965) state that all accomplished esophageal speakers produce a clearly audible "trapping noise."

Several investigators mention the considerable difficulty of eliminating klunking, once established (Diedrich, 1971; Gardner, 1978; Martin, 1963; Salmon, 1971; Shanks, 
1977). Martin (1963) states that intake noise production is probably related to anatomic and physiologic differences in those speakers who produce such sounds. Martin suggests even a qualified speech instructor is unlikely to correct the problem. The majority of the authors cited above do not address the question of physiologic and anatomic differences as a factor in klunking. Gardner (1978), Greene (1957), and Salmon (1971) refer to the habitual nature of klunking. This might imply they regard klunking as learned behavior. The classification of klunking as a learned behavior does not make it simple to extinguish, but does perhaps offer more hope for improvement than an assumption of physiologic or anatomic anaomaly.

One physiologic condition which might seem to have an influence on an esophageal speaker's perception of intake noise is his or her hearing acuity. Studies by Martin, Hoops, and Shanks (1974) demonstrate a positive correlation between poor audition and poor esophageal speech skill. Such results underscore the necessity for hearing screening of all candidates for esophageal speech training but do not specifically address the problem of klunking. Since klunking noise is generally reported to be relatively low pitched, it would seem reasonable to assume that many esophageal speakers have sufficient hearing acuity to perceive the sound. It is possible, however, that many 
speakers who klunk learn to adapt to and ignore the behavior.

A partial list of methods of treatment for air intake klunk noise would include the following: muscular relaxation techniques, alteration of speed and/or volume of air intake, use of a stethoscope or other amplification devices to enhance the clients' sensation of the klunking act, negative practice, and positive reinforcement of non-klunking intakes. Shanks (1977) states that while klunking can be eliminated by changing the force or brevity of injection, very few laryngectomees actually do eliminate the klunk. Shanks suggests considering a change to consonant injection as the primary means of intake, as he believes to continue standard injection technique may lead to reinforcement of the klunking behavior. Shanks, like Greene (1957) and Salmon (1971), stresses the importance of recognition and treatment of klunking early in the course of speech instruction. Gardner (1978) advocates modeling and reinforcing a quiet, relaxed intake. If klunking persists, Gardner suggests considering use of the inhalation technique of air intake. Diedrich (1971), Duguay (1977), and Salmon (1971) encourage the clinician to identify and reinforce those air intakes which do not include klunking noise. Virtually all published sources of information on esophageal speech instruction encourage patience on the part of instructor and student. A step-by-step progression of mastery from sound 
to syllable to word to phrase, etc. is widely advocated. None of the references cited above provides data on the efficacy of techniques to manage klunking noise. The degree to which air intake noise may influence communication is largely unreported in the literature. Since klunking usually occurs immediately prior to each utterance, some authors describe it as a distraction, rather than a direct interference to speech (Hyman, 1979; Shanks, 1979). No references identify the specific characteristics of klunking behavior which might cause it to be distracting to the listener. Hyman (1979) states that klunking noise may not affect intelligibility, but may adversely influence oral communication.

Since klunking usually occurs immediately before onset of voice, it does not compete directly with speech sounds. Shanks (1979) includes klunking with a group of distracting behaviors which are "not phonemic and not truly speech elements," but which influence intelligibility by distracting listener attention. Hyman (1979) also describes klunking behavior as a distraction rather than a direct interference.

In summary, the literature has identified esophageal air intake noise (more specifically, klunking) as a problem for many alaryngeal speakers, but has not defined its incidence or severity. Research has suggested possible etiology, but not conclusively. Treatment procedures described 
appear to have been based on anecdotal evidence. The understanding of esophageal air intake noise might be facilitated by the identification of measurable correlates to listener acceptability of such noise. The apparent lack of objective criteria for listener judgments was the primary motivation for the present study. 


\section{CHAPTER III}

\section{METHODS AND PROCEDURES}

\section{SUBJECTS}

The sample was comprised of twenty-four volunteer laryngectomees who were attending the XIV Annual Institute in Laryngectomee Rehabilitation at Eastern Washington University, Cheney, washington, 1981. The only criterion for participation was the ability to read the sample paragraph aloud.

\section{RECORDING EQUIPMENT AND PROCEDURES}

Audio-tape recording was performed in the audiometric suite at Eastern Washington University. Equipment consisted of a SONY model 366 reel-type recorder, an Electrovoice model 631B dynamic microphone, and Maxell UDXL high-output, low-noise magnetic tape. The VU meter was adjusted to peak at "zero" for each subject and the tape speed set at 7.5 inches per second. The microphone was mounted on a stand such that the receiving end was situated approximately one foot in front of and one foot to the side of the subject's mouth. This placement appeared to minimize microphone pickup of extraneous body movement and stoma noise yet provided clear recording of speech and air intake noise. 
Recordings were conducted between the hours of 9:00 A.M. to 4:30 P.M. allowing at least forty-five minutes from the most recent meal to minimize possible influence of feeding on esophageal function. After explaining the purpose and securing written consent, each subject was instructed to read aloud the first paragraph of the "Rainbow Passage" (Fairbanks, 1960) twice for practice. This enabled the subjects to adjust to the soundproof booth and to "warm up" their esophageal voices. Each subject cued the investigator when he or she was ready to begin.

\section{RATING SESSIONS}

Judges

Four judges were obtained from the distinguished faculty of the XIVth Annual Institute in Laryngectomee Rehabilitation, Eastern Washington University, 1981. Each judge had professional experience with hundreds of layngectomees over a minimum of twenty years as a speech clinician. Hearing sensitivities of the judges were within normal limits for speech.

Equipment and Procedures for Air Intake Acceptability Ratings

To avoid group influence on the ratings, each judge had an individual listening session. These sessions were conducted in an audiometric control booth, using a sONY model 366 tape recorder and TDH-39 headphones. The 
recordings were presented in a random order at a mean listening level of $70 \mathrm{~dB}$, SPL. The tape was stopped for two minutes after each ten minutes of play, to minimize listener fatigue. Each listener unknowingly rejudged four of the recordings, to sample intrajudge reliability. Esophageal air intake noise was rated on a five-point equal-appearing interval scale with number one being the least acceptable air intake noise and number five indicating the most acceptable (Appendix A).

Procedures for Overall

Proficiency Ratings

Overall esophageal speech proficiency ratings were available for eighteen of the twenty-four subjects. These proficiency assessments were done by the faculty of the laryngectomee institute as part of the normal proceedings. Although the proficiency ratings and the intake acceptability ratings took place at the same week-long institute and shared some of the same judges, the ratings were conducted independently. The procedures and conditions for the proficiency ratings were quite different from those of the intake noise acceptability ratings. Proficiency was judged during direct observations of each subject as he or she spoke briefly to a group in a university lecture hall. A six-point scale was used, with number one being "very strong" and number six being "no voice" (Appendix B). The proficiency scores were reversed for the statistical 
comparison with the present study. For example, number one on the proficiency scale was changed to represent "no voice" and number six to indicate "very strong." This score reversal insured that both the proficiency scale and the intake acceptability scale had the same numerical direction, i.e., numerically higher scores on either scale were indicative of superior performance.

\section{RAW DATA ANALYSIS}

Instrumentation

An acoustic analysis of the recorded speech samples was performed with the aid of a Visi-pitch, model 6087, frequency and amplitude extractor, connected to a Tektronix storage oscilloscope. This instrumentation produced a graphic display of relative intensity over time. A foursecond display time was used for this study. Several foursecond segments of each sample were photographed for a permanent record. Each photograph was annotated, syllable by syllable, to insure correspondence with the particular segment of speech being displayed on the oscilloscope.

\section{Procedures}

Mean Intensity of Speech and Air Intake Noise. Intake noise was readily identified on the oscilloscope display as it typically preceded and followed speech signals of greater amplitude and duration. Examples of this noise are observable in Figure 1. The relatively smooth, straight sections 
of the oscilloscope trace represent the noise floor of the tape recording. Syllables are seen as the higher peaks (see "into," "many," and "beautiful," Figure I) while the intake noises are displayed as much lower peaks of brief duration (see short peaks immediately preceding labelled syllables, Figure 1). Due to the thickness of the trace line, the durations of very brief events were difficult to measure reliably and were, therefore, not included in this study. Intensity peaks, however, were easily read on the grid scale. On the vertical axis of the display, each large grid square represents $10 \mathrm{~dB}$ SPL. Horizontally, each large grid square represents .4 seconds.

The Number of Syllables per Air Intake. The number of syllables uttered in a given sample was divided by the number of audible air intakes in the sample. The resultant values were expressed as syllables per intake.

Rate of Speech. Each sample was timed with a handheld quartz-crystal chronograph watch. The number of syllables uttered per sample was divided by its timed length. Thus, the rate of speech for samples in this study is shown as syllables per second. Speech rate is more commonly expressed as the number of words per minute, but a finer measure seemed more appropriate for the short samples used in this study. 


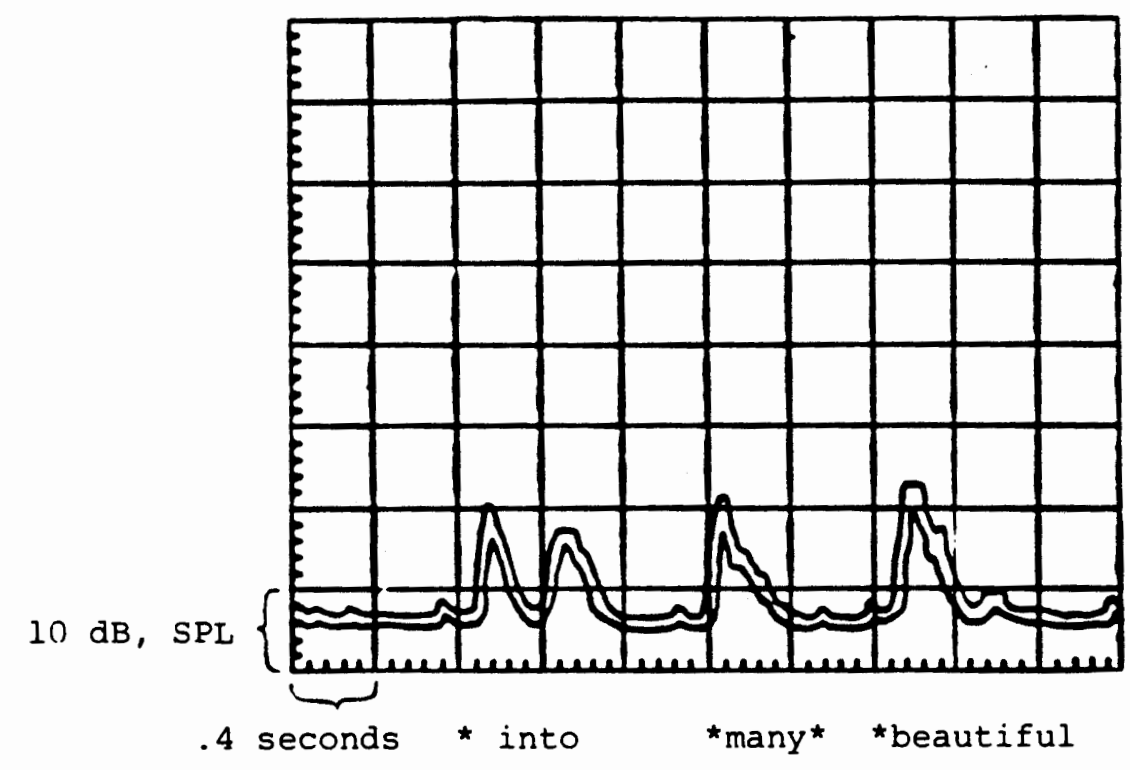

Figure 1. Overlay traced from a photograph of Visi-pitch, model 6087, display of the esophageal speech sample from subject number 5 . Asterisks represent esophageal air intakes.

\section{STATISTICAL ANALYSIS}

The statistical analysis of the data was used to assess intrajudge and interjudge reliability, and to determine the significance of correlation between the judges' ratings and the objective measures.

Interjudge Reliability

The Pearson product-moment correlation coefficient $(r)$ for the ratings from each judge compared with the mean ratings from all judges ranged from .78 to .86 (Table I). 
TABLE I

CORRELATION BETWEEN EACH JUDGE'S RATINGS AND THE MEAN-OF-JUDGES RATINGS

\begin{tabular}{ccc}
\hline Judge & $r$ & Significance Level \\
\hline A & 0.86 & .01 \\
B & 0.78 & .01 \\
C & 0.80 & .01 \\
D & 0.82 & .01 \\
\hline
\end{tabular}

Intrajudge Reliability

The internal consistency of the judges was sampled by having them unknowingly rejudge four of the subjects. The $r$ values and corresponding significance levels for the testretest scores ranged from .88 to .98 (Table II).

TABLE II

CORRELATION BETWEEN EACH JUDGE'S TEST AND RETEST RATINGS OF SELECTED SUBJECTS

\begin{tabular}{ccc}
\hline Judge & $r$ & Significance Level \\
\hline A & 0.96 & .05 \\
B & 0.88 & .10 \\
C & 0.95 & .05 \\
D & 0.98 & .02 \\
\hline
\end{tabular}

Correlation of Objective Measurements with Listener Judgments of Acceptability

The mean-of-judges rating for each of the twenty-four subjects was entered into a multiple regression analysis (Kim \& Kohout, 1975) which compared the ratings with the 
objective measures of esophageal speech used in the study. This analysis yielded the Pearson product-moment correlation coefficient $(r)$, the coefficient of determination $\left(r^{2}\right)$, and beta value for each variable. The correlation coefficient indicates the degree to which any of the objective measurements is related to the judges' ratings. The coefficient of determination indicates the percentage of the total variance of judges' ratings which can be accounted for by the measurements included in the regression formula. $F$ values were computed for each measurement variable and compared with a table of critical values for $F$, at the .01 level. The beta values may be used in a prediction formula to estimate the probable air intake noise acceptability rating for a subject, given only the objective measurements of the subject's voice.

Association of Listener Judgments of Speech Proficiency and Noise Acceptability

Independently conducted speech proficiency ratings for eighteen of the subjects were compared with the intake noise ratings obtained from the present study. The overall speech proficiency scores were included as predictor variables in the multiple regression analysis described above. 


\section{CHAPTER IV}

\section{RESULTS AND DISCUSSION}

The results of this study are presented in the order of the questions asked. The latter subsection of this chapter is devoted to an interpretation of the results.

\section{RESULTS}

Are Selected Objective Measures of Esophageal Speech Significantly Correlated with Sophisticated listener Judgments of Air Intake Noise Acceptability?

Intake noise acceptability ratings were found to be significantly correlated with four of the five measurements used. Those measurements were: the number of syllables uttered per air intake, the rate of speech, the mean intensity intake noise, and the ratio of mean air intake noise intensity to mean speech intensity. Mean intensity of speech was insignificantly correlated to intake acceptability. The multiple regression analysis indicated that approximately 83 percent of the total variance in the listener ratings of air intake noise acceptability could be accounted for by the measured variables. The measurement which exhibited the most predictive strength was the number of syllables uttered per intake. Computed $F$ values for each 
variable exceeded critical values of $F$ beyond the .01 level. The results of the statistical analysis for each parameter are described below and presented in Table III.

The Mean Intensity of Air Intake Noise. Intake noise intensity was found to be inversely associated to the judges' rating of intake noise with a correlation coefficient $(r)$ of -.71 . In other words, greater intensity of intake noise tended to lower listener acceptability. This is significant at the .01 level with twenty degrees of freedom. The coefficient of determination $\left(r^{2}\right)$ change caused by including intake noise intensity into the regression was .13 , indicating this variable accounted for approximately 13 percent of the total variance of the intake noise acceptability ratings.

The Mean Intensity of Speech. Mean speech intensity was associated with intake acceptability ratings below the .10 level of significance, with an $r$ value of -.14. The $r^{2}$ change for this parameter accounted for less than 1 percent of the total variance of listener ratings.

The Ratio of Mean Speech Intensity to Mean Air Intake Noise Intensity. With a simple $r$ value of .46 , the ratio of speech to intake noise intensity was positively correlated with intake noise acceptability at the .05 level of significance. Despite the size of the simple correlation, the regression results indicated that this parameter was a weak predictor of intake noise acceptability, accounting for less 


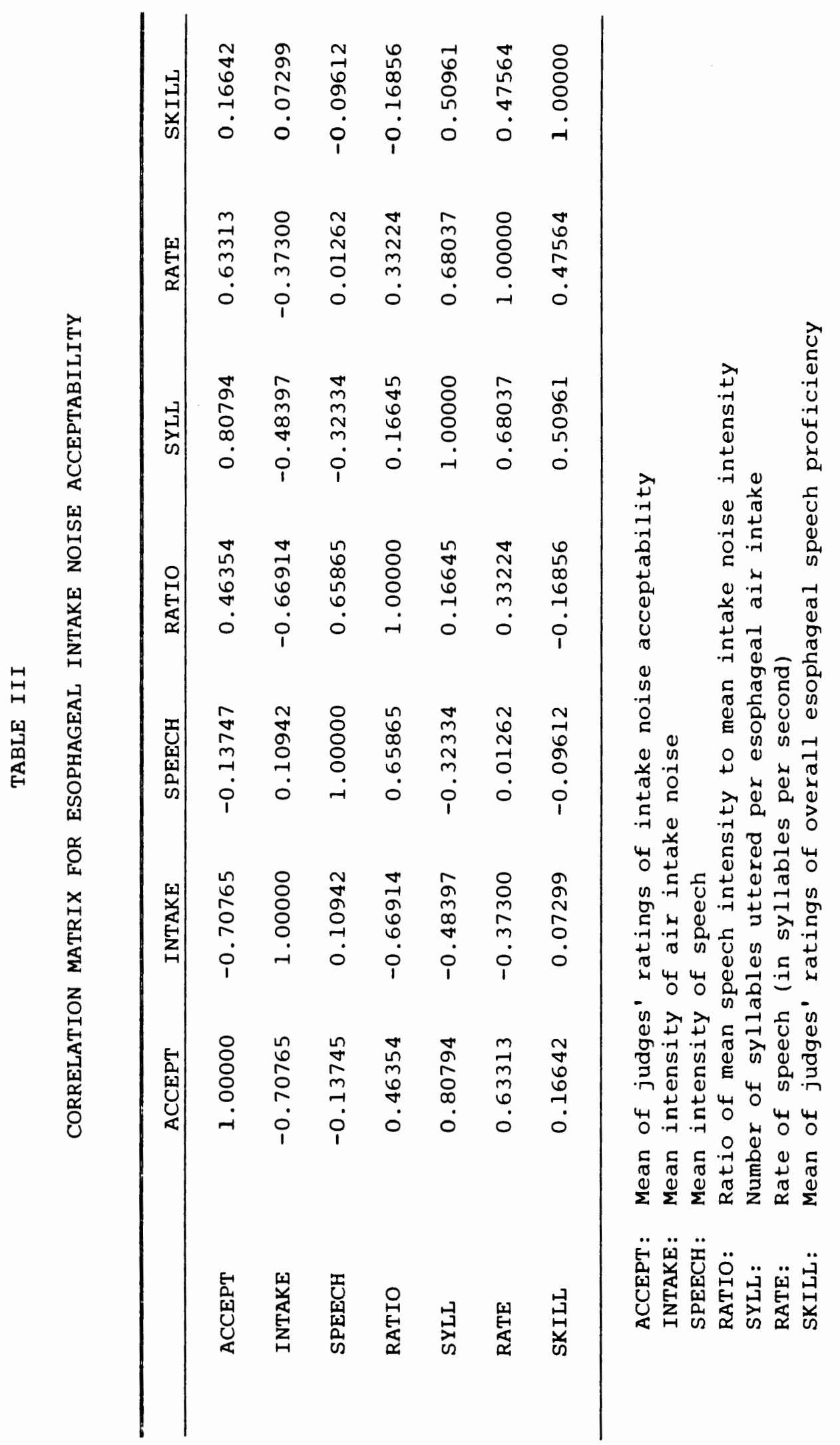


than 1 percent of total variance. Simply put, there was a weak tendency for intake noise acceptability to increase as the difference between speech intensity and intake intensity increased.

The Number of Syllables Uttered Per Audible Intake.

This was the strongest variable of the study, both in simple correlation and in predictive value. The positive $r$ of .81 was significant at the .01 level. This variable accounted for 65 percent of the variance in listener ratings of intake noise.

The Rate of Speech. Speech rate was positively correlated with intake noise ratings at the .0l level of significance, with an $r$ value of .63 . The multiple regression, however, showed only 1.5 percent of the total variance of intake noise ratings to be accounted for by rate.

Are Sophisticated Listener Judgments of Overall Esophageal Speech Proficiency Significantly Correlated with Sophisticated Listener Judgments of Air Intake Noise Acceptability?

The statistical analysis revealed that ratings of overall esophageal speech proficiency were not significantly related to the ratings of air intake noise acceptability. The $r$ value of .17 was indicative of a weak correlation. The multiple regression analysis indicated that overall speech proficiency ratings accounted for about 2 percent of the total variance of the intake noise acceptability ratings. 


\section{DISCUSSION}

Are Selected Objective Measures of

Esophageal Speech Significantly Correlated with Sophisticated Listener Judgments of Air Intake Noise Acceptability?

The results suggest that of the variables compared, the number of syllables uttered per air intake was by far the strongest predictor of sophisticated listener acceptance of esophageal air intake noise. Mean intensity of intake noise was also predictive, but to a far lesser extent than the number of syllables per air intake. The rate of speech and the ratio of speech intensity to intake noise intensity were significantly correlated with listener acceptance of intake noise, but were weak predictors of such acceptance. Mean speech intensity was insignificantly correlated with listener acceptance of intake noise.

The predictive power of independent variables in a multiple regression analysis is affected by the particular variables included in the computation. Given the extremely complex nature of the perceptual task of judging voice, it is very unlikely that all appropriate measurable variables were included in the present study. It is also probable that not all the variance of intake noise acceptability ratings can be accounted for by physical correlates. Despite these limitations, the results of the present study reveal clear differences in the predictive value of the measurements used in this study. 
The number of syllables uttered per esophageal air intake has been identified as one of the skills associated with the acquisition of esophageal speech (Berlin, 1963; Damste, 1979; Gardner, 1978; Snidecor \& Curry, 1959). This measure has usually been obtained by counting a subject's repetitions of a designated monosyllable. The repetition of a monosyllable obviously differs from the task used for the present study, the production of connected speech. The purpose of measuring syllables per intake in the present study was not to compare the results directly with previous data. Rather, the principle rationale was to provide a simple and sensitive indicator of the frequency of occurrence of audible air intakes. For example, five syllables per intake would indicate that the subject produced an audible air intake every five syllables.

The strong correlation between syllables per intake and intake noise acceptability is perhaps best explained if the syllables per intake parameter is looked at as the rate of occurrence of air intakes. From this perspective, the listeners tended to judge intake noise more favorably as the number of intakes decreased. While it is not surprising that listener acceptability of intake noise would improve as the quantity of intakes decreased, it is interesting that this parameter (syllables per intake) was so much stronger a predictor of acceptability than the intensity of intake noise. Apparently, the listeners could accept higher intake 
noise intensity levels if the intakes did not occur too frequently.

Many clinicians are familiar with esophageal speakers who have rather loud intake noises, but otherwise superior esophageal voice. Perhaps if the speech intensity of such speakers is sufficiently high, it can compensate for above average intake noise intensity. To test this hypothesis, the present study included the ratio between mean speech intensity and mean intake intensity in the statistical analysis. The supposition was that a higher ratio would be predictive of better acceptability. The results fail to support this hypothesis. The speech-to-intake intensity ratio was moderately correlated with intake noise acceptability $(r=.46)$ but had negligible predictive value (less than 1 percent of total variance).

The mean speech intensity measurements of the speakers were insignificantly correlated with both intake noise acceptability ratings and overall speech proficiency ratings. Since mean speech intensity is one component of the previously described speech-to-intake intensity ratio, it would seem logical that it too would be weakly related to intake acceptability ratings. The low correlation of speech intensity with overall esophageal speech proficiency is consistent with the findings of Hoops and Noll (1969).

Rate of speech was moderately correlated with intake noise acceptability, but accounted for less than 2 percent 
of the total variance of those ratings. Rate is a parameter which has been associated with esophageal speech proficiency (Snidecor \& Curry, 1959; Hoops \& Noll, 1969). This association, however, does not assure that a faster rate of speech will be predictive of intake noise acceptability, since intake noise is but one of many factors which may influence overall speech proficiency ratings.

Are Sophisticated Listener Judgments of Overall Esophageal Speech Proficiency Significantly Correlated with Sophisticated Listener Judgments of Air Intake Noise Acceptability?

The results suggest that the sophisticated listeners' ratings of overall esophageal speech proficiency had little association with their ratings of air intake noise acceptability. While klunking, the most common esophageal air intake noise, has frequently been described as a problem requiring attention, the results of the present study suggest that it has little impact on sophisticated listener judgments of overall proficiency. A probable rationale for this mild influence lies in a primary temporal characteristic of esophageal inflation: it is usually pre-phonatory. Klunking may distract the listener, but apparently not often enough to impair communication seriously. 
CHAPTER V

SUMMARY AND IMPLICATIONS

SUMMARY

The literature on esophageal speech has identified the problem of extraneous air intake noise, suggested its possible etiology, and provided practical advice for clinical management. Documentation on the efficacy of specific methodology is lacking in the literature. Such documentation would be simplified if objective criteria were used to rate the severity of intake noise. The present study was prompted by the lack of basic data regarding listener evaluation of intake noise.

The purpose of this study was to identify physical and perceptual correlates of acceptability of esophageal air intake noise. A primary and a secondary question were asked:

Are selected objective measures of esophageal speech significantly correlated with sophisticated listener judgments of air intake noise acceptability? The measures used were:

1. The mean intensity of air intake noise

2. The mean intensity of speech

3. The ratio of mean speech intensity to mean intake noise intensity 
4. The number of syllables uttered per intake

5. The rate of speech (in syllables per second)

Secondarily, are sophisticated listener judgments of overall esophageal speech proficiency significantly correlated with sophisticated listener judgments of air intake noise acceptability?

Twenty-four laryngectomees, ranging widely in esophageal speaking ability, read a standard passage for audio tape recording. Four expert voice clinicians listened to the tapes, rating subjects on the acceptability of air intake noise. Overall esophageal speech proficiency ratings for eighteen of the subjects were obtained from an independent study conducted during the same week.

Five objective measures of esophageal speech were extracted from each speech sample, using a real-time intensity display instrument and a storage oscilloscope.

Interjudge and intrajudge reliability were determined by computing Pearson product-moment correlation coefficients. The means of the ratings on intake noise acceptability were entered in a multiple regression analysis as the criterion variable, with the objective measurements and the overall speech proficiency ratings as the predictor variables.

Three of the predictor variables were found to be positively correlated with the air intake acceptability ratings beyond the .01 level of significance: the number of 
syllables uttered per air intake, the mean intensity of speech, and the rate of speech. The ratio of mean speech intensity to mean intake noise intensity was correlated to intake noise acceptability at the .05 level. Neither mean speech intensity nor the overall esophageal speech proficiency variables were significantly correlated with intake noise acceptability. The number of syllables uttered per intake accounted for the largest share of the variance of intake noise acceptability. Mean intake intensity was the second, but far weaker predictor of variance. The remaining variables accounted for a very slight percentage of the total variance.

\section{IMPLICATIONS}

\section{Clinical}

Two main implications emerged from these results, and the findings of a previous investigation were supported. The first significant finding was that the number of syllables uttered per intake (the rate of intake occurrence) was a stronger predictor of intake noise acceptability than mean intake intensity. This suggests that clinic and practice time might be better spent improving the duration of speech per audible intake rather than working directly on quieting the intake noise. The results suggest that even if the intake noise intensity remains static, an increase in the production of syllables per audible intake may improve 
both intake noise acceptability and overall speech proficiency ratings.

The finding that intake noise acceptability is not a significant correlate of overall esophageal speech proficiency also would imply that practice be concentrated on other aspects of speech, such as rate, duration, vocal quality, prosody, inflection, etc.

The finding which supports Hoops and Noll's (1969) previous conclusion that intensity of esophageal speech is not significantly related to proficiency might be of interest to those who arduously struggle to increase volume at the expense of other more significant parameters.

\section{Future Research}

Future researchers may wish to improve upon the methods used in the present study and to include other parameters.

The intake noise acceptability ratings may have been somewhat compressed by the combination of very few judges and a narrow range of possible scores for each subject. With only four judges, the impact of a single judge's rating can sharply affect the mean for any given subject. This problem could be minimized by using an expanded rating scale or more judges, or perhaps both.

Future researchers may be able to extract more information by means of statistical analysis. Partitioning the group by standard deviation breaks or quartiles might yield 
more specific data about the characteristics of those subjects sharing a similar level of proficiency. Using a larger sample could yield valuable normative data. Such data might be used to set measurable progress goals which would bear a strong relationship to listener evaluations. The clinical implications from the present study could be readily tested with a few cooperative laryngectomees. The next logical step for the present study, however, would be to use naive listeners as judges and to compare the results with those of the sophisticated listeners. A well-equipped speech science laboratory might choose to explore the possible effects of spectral components and temporal relationships. Intake latency, pause time, position of intake within a pause, and rate of multiple intakes are all accessible parameters which have not been systematically compared with listener ratings. It would seem quite plausible that a listener could be more likely to notice an extraneous speech sound if that sound were "telegraphed," so to speak, by an overly long pause and/or multiple inflations within a pause.

Finally, a spectral analysis of esophageal air intake noise might yield a more precise description of the klunk and perhaps a clearer insight as to its etiology. 


\section{REFERENCES}

AMERICAN CANCER SOCIETY. Facts on cancer of the larynx. New York: American Cancer Society, 1978.

BERLIN, C. I. Clinical measurement of esophageal speech: I. methodology and curves of skill acquisition. Journal of Speech and Hearing Disorders, 1963, 28, 42-51.

BERLIN, C. I. Hearing loss, palatal function, and other factors in post laryngectomy rehabilitation. Journal of Chronic Disorders, 1965, 30, 174-183.

BROWN, F. L., AMOS, J. R. \& MINK, O G. Statistical concepts, a basic program. New York: Harper and Row, 1975 .

DAMSTE, P. H. Rehabilitation score-list for the laryngectomized. In R. L. Keith \& F. L. Darley (Eds.), Laryngectomee rehabilitation. Houston: College Hill Press, 1979.

DIEDRICH, W. M. The mechanism of esophageal speech. Annals of the New York Academy of Sciences, 1968, 155, 303-317.

DIEDRICH, W. M. Primary stages of teaching. In $S$. Rigrodsky, J. Lerman, \& E. Morrison (Eds.), Therapy for the laryngectomized patient. New York: Teachers College Press, 1971.

DIEDRICH, W. M. \& YOUNGSTROM, K. A. Alaryngeal speech. Springfield, Ill.: Charles C. Thomas, 1966.

DUGUAY, M. J. Esophageal speech. In M. Cooper \& M. H. Cooper (Eds.), Approaches to vocal rehabilitation. Springfield, Ili.: Charles C. Thomas, 1977.

FAIRBANKS, G. Voice and articulation drillbook (2nd edition). Philadelphia: Harper and Row, 1960.

FILTER, M. H. Rating systems for esophageal speakers. Unpublished doctoral dissertation, Bowling Green University, 1971 . 
GARDNER, W. H. Laryngectomee speech and rehabilitation. springfield, Ill.: Charles C. Thomas, 1978.

GREENE, M. C. L. The voice and its disorders. London: Pitman, 1957.

HOOPS, H. R. \& NOLL, J. D. Relationship of selected acoustic variables to judgements of esophageal speech. Journal of Communication Disorders, 1969, 2, 1-13.

HORN, D. Laryngectomee survey report. Presented at the Eleventh Annual Meeting, International Association of Laryngectomees, Memphis, Tennessee, August 21, 1962.

HYMAN, M. Factors influencing intelligibility of alaryngeal speech. In R. L. Keith \& F. L. Darley (Eds.), Laryngectomee rehabilitation. Houston: College Hill Press, 1979.

HYMAN, M. Intermediate stage of teaching alaryngeal speech. In S. Rigrodsky, J. Lerman, \& E. Morrison (Eds.), Therapy for the laryngectomized patient. New York: Teachers College Press, 1971.

KALLEN, L. A. Vicarious vocal mechanisms, the anatomy, physiology, and development of speech in laryngectomized persons. A.M.A. Archives of Otolaryngology, $1934,20,460-503$.

KIM, J. \& KOHOUT, F. J. Multiple regression analysis: subprogram regression. In W. R. Klecka, N. H. Nie, \& C. H. Hull, SPSS primer: Statistical package for the social sciences. New York: McGraw-Hill, 1975.

LAUDER, E. Self-help for the laryngectomee. San Antonio: Edmund Lauder, 1972 .

LUCHSINGER, D. \& ARNOLD, G. Voice-speech-language, clinical communicology: its physiology and pathology. Belmont, Calif.: Wordsworth, 1965.

MARTIN, D. E. Evaluating esophageal speech development and proficiency. In R. L. Keith \& F. L. Darley (Eds.), Laryngectomy rehabilitation. Houston: College Hill Press, 1979 .

MARTIN, D. E., HOOPS, H. R., \& SHANKS, J. C. The relationship between esophageal speech proficiency and selected measures of auditory function. Journal of Speech and Hearing Research, 1974, 74, 80-85. 
MARTIN, $H$. Rehabilitation of the laryngectomee. Cancer, 1963, 16, 559-574.

SALMON, S. J. Use of imagery in teaching esophageal speech. California Journal of Communicative Disorders, 1971 , $2,17-24$.

SHAMES, G. H., FONT, J., \& MATHEWS, J. Factors related to speech proficiency of the laryngectomized. Journal of

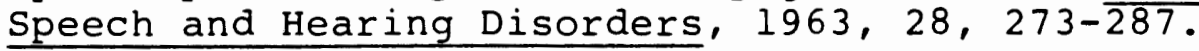

SHANKS, J. C. Developing esophageal communication. In R. L. Keith \& F. L. Darley (Eds.), Laryngectomee rehabilitation. Houston: College Hill Press, 1979.

SHANKS, J. C. Variations on a vocal theme through interpersonal therapy with alaryngeal patients. In $M$. Cooper \& M. H. Cooper (Eds.), Approaches to vocal rehabilitation. Springfield, Ill.: Charles C. Thomas, 1977.

SHIPP, T. Frequency, duration, and perceptual measures in relation to judgements of alaryngeal speech acceptability. Journal of Speech and Hearing Research, 1967 , $10,4 \overline{17}-4 \overline{2} \overline{7}$.

SNIDECOR, J. C. Speech rehabilitation of the laryngectomized. springfield, Ill.: Charles C. Thomas, 1968.

SNIDECOR, J. C. \& CURRY, E. T. Temporal and pitch aspects of superior esophageal. Annals of Otology, Rhinology, and Laryngology, 1959, 68, 1-14.

WALDROP, W. \& GOULD, M. A. Your new voice. Chicago: American Cancer Society, 1956. 


\section{APPENDIX A \\ INSTRUCTIONS READ TO JUDGES}

You will be listening to recorded speech samples from alaryngeal speakers. Please rate the acceptability of esophageal air intake noise for each speaker on a five-point scale, with number one representing the least acceptable intake noise and number five the most acceptable intake noise. Please do not judge stoma noise or overall esophageal speaking proficiency.

ACCEPTABILITY SCALE FOR ESOPHAGEAL AIR INTAKE NOISE

LEAST ACCEPTABLE

MOST ACCEPTABLE 


\section{APPENDIX B}

ESOPHAGEAL SPEECH PROFICIENCY SCALE USED BY THE $14 \mathrm{TH}$ ANNUAL INSTITUTE IN LARYNGECTOMEE REHABILITATION, EASTERN WASHINGTON UNIVERSITY, 1981

$$
\begin{aligned}
& 1 \text { - very strong } \\
& 2 \text { - strong } \\
& 3 \text { - average } \\
& 4 \text { - weak } \\
& 5 \text { - very weak } \\
& 6 \text { - no voice }
\end{aligned}
$$

